See discussions, stats, and author profiles for this publication at: https://www.researchgate.net/publication/330300900

\title{
Book review: Building a Capable State: Service Delivery in Post-Apartheid
} South Africa

Article in Urban Studies · January 2019

DOI: $10.1177 / 0042098018820183$

CITATIONS

0

1 author:

Laurence Piper

University of the Western Cape

96 PUBLICATIONS 509 CITATIONS

SEE PROFILE

Some of the authors of this publication are also working on these related projects:

Project Zuluness, nationalism and South African politics View project

Project Freedom, Power and Representation View project
READS

75 


\section{Book review}

Ian Palmer, Susan Parnell and Nishendra Moodley, Building a Capable State: Service

Delivery in Post-Apartheid South Africa, Zed: London, 20I7; 303 Pp.: ISBN 978-I-78360964-2, $£ 24.99$ (pbk)

Reviewed by: Laurence Piper (D), Political Studies, University of the Western Cape, South Africa

Written by long-standing research practitioners Ian Palmer and Nishendra Moodley, as well as one of South Africa's leading academic urbanists, Professor Sue Parnell, Building a Capable State tackles the hard question of whether the post-apartheid state is up to delivering rights-based, sustainable development, and more specifically the task of providing local services like water, electricity, roads and housing.

Somewhat surprisingly, after 10 years of maladministration and even deliberate sabotage under the Zuma administration, the answer is a qualified yes. Today South Africa's citizens, especially poor citizens, are substantially better off than they were in 1994. They have access to more and better services, and this access has brought a small but real decline in poverty. At the same time, however, the gap between rich and poor has widened, and the last 10 years has seen a significant weakening in state performance.

While these general claims are qualified in important ways, the overall assessment of both service delivery and the capacity of the state is largely positive. This is important, as many citizens and observers of South Africa
Urban Studies

I-3

(C) Urban Studies Journal Limited 2019 Article reuse guidelines: sagepub.com/journals-permissions DOI: $10.1177 / 0042098018820183$ journals.sagepub.com/home/usj (s)AGE are inclined to judge the state and country more harshly than the evidence suggests. In this respect, Building a Capable State is an important corrective to uncritical pessimism about post-apartheid South Africa.

Where the book really excels is in providing systematic, thorough and up-to-date evidence, demonstrating through data the performance of each sector in great detail, and usually also in comparison with other middle-income countries. Seen down time and through a comparative lens, the authors do an unparalleled job of situating the reader in the textured landscape of local service delivery. Another great strength of the book is explaining systematically the legal, policy, institutional, programmatic and organisational context of local governance. For any student, scholar or practitioner of the state or development, this makes the book essential reading, and a necessary starting point for any research on water, electricity, roads and housing.

There is more though. To my mind, three key theoretical insights are affirmed in the book. The first, which underpins the central claim of the book, is that building the capacity of the state is a process best understood over the longue durée. Thus, the authors characterise the capability building of the post-apartheid state down time as follows: a period of freedom and re-organisation from 1994 to 2000; a period of growth and implementation from 2001 to 2008; and a period of ailing economy and disheartened citizenry from 2008 onwards. Although the authors do not use the term longue durée, nor cite 
the Annales school, an emergent theme is that the state is like the Titanic - hard to build, slow to turn around, but still vulnerable to Gupta icebergs (my clumsy metaphor, not the authors').

While the book does a good job of reminding the reader not to judge the capability of the state by the Zuma years alone, it simultaneously demonstrates how this capability is fractured by time, place and sector. Historically the book demonstrates how uneven spatial patterns in performance today reflect the decades of effective governance in South Africa's major cities in stark contrast to the rural areas, especially those designated as homelands under grand apartheid. In addition, and this is a claim that the authors could do more to advocate, there has been a clearly urban bias in the design of local government institutions, policies and programmes that has reinforced the historical advantage of cities and held back advances in the rural areas. Examples abound, including the poor design of rural local government (no clear role for traditional leaders, and district councils are mostly redundant), the focus by national departments on cities not rural areas and the marked contrast in delivery of quality roads, electricity and water between cities and the countryside.

Lastly, there is clear evidence of significant variation in performance by sector as well as spatially and down time. Thus some sectors have done remarkably well, like electricity (until recently), sanitation less so, while others like housing have muddled along. The book does a better job of describing these differences than explaining them, but a key variable that emerges is the capacity of national departments to support local service delivery. This is a story in significant part about weaknesses in the political system: nepotism, party-deployment and factional conflict.
The second theoretical insight of the book is the claim that the appropriate way to theorise whether the state can achieve its service delivery and developmental promises is through the concept of 'capability' rather than 'capacity'. Although the latter is commonly used in local government, as the authors persuasively point out capability involves 'more than human, natural and financial resources, and systems, but also the values, relationships and organisational culture' (p. 9) necessary for effective development. On this basis, they develop a four-fold schema of capability, including environmental (socio-economic and demographic conditions), institutional (actors and rules), organisational (internal policies, skills and culture) and individual.

Echoing the famous insight of Amartya Sen and Martha Nussbaum on reframing development in terms of capabilities, the authors rethink the development of the state in a similar way, although implicitly rather than explicitly. This framework is applied somewhat unevenly across the chapters, but elements come out clearly in respect of two recurring organisational capacity challenges: the lack of engineering skills, and the failure of leadership, especially national leadership to adequately support local government. In a context where technocratic governance is often wrongly criticised as inherently neoliberal or anti-political, this book offers an important corrective. Indeed, it affirms the centrality of both technical and political skills, and the balance between them, to sustainable development.

The third enduring theoretical insight of the book is that understanding delivery at the local level requires understanding much more than local government, but especially the control and support given to local government by provincial and national departments. Not only is national government repeatedly at fault for not doing enough in this regard, but the authors make the case 
for enhancing devolution to the local level at least in respect of well-functioning metropolitan councils that they argue should take the lead in public transport and housing delivery. Informed by the recognition that local government cannot deliver development on its own, even in the well-off metros, the authors criticise government for a failure to develop meaningful partnerships of coproduction with business and communities.

As a work focused primarily at the higher level of the functioning of the state in local service delivery, and especially infrastructural aspects of this, the book is simply excellent. In addition, the sector chapters on water, electricity, roads and housing are state of art overviews. Of course, with any argument of this breadth it will cover in passing many intriguing and complex issues to an extent unsatisfactory to the specialist.
But to judge it harshly in this regard would be unfair. My main criticisms of the book are that the authors could have done more to distil some of the theoretical learnings more explicitly and also to reflect on areas that need more analysis. In respect of the latter, I think the book leaves room for more explanation of the variances in sectoral performance, as well as the lack of national government support. But let me not nit-pick too much. This is an excellent, timely and important book, and essential reading for all researching or working on service delivery, local government, developmental state and water, electricity, roads and housing.

\section{ORCID iD}

Laurence Piper (DD https://orcid.org/0000-00020061-0736 